\title{
7. Stories from Childhood: Windows on experience or cultural meta-narratives? Evidence from Papua New Guinea
}

\author{
Stephen C. Leavitt
}

\section{Introduction}

Childhood stories in personal narratives of Western subjects often convey pivotal moments of experience aimed at communicating personal identity. Such strategies rely on cultural models that see identity as the product of past life events, with childhood experience especially important. But what do personal childhood stories reveal in societies with very different cultural models of early life's role in shaping identity? Among the Bumbita Arapesh of Papua New Guinea - a group bordering the Ilahita Arapesh — childhood is the time of life when a new growing being takes in essential life substance from parental nurturing, supplemented by ritual transformation in initiation and maturation ceremonies. In their view, childhood experiences do little to shape personality; instead, they work to define one's essential being, in substance and position, through nurturing and transactions of food. Individuals' stories of their childhood, then, convey themes of personal identity as refracted through local Bumbita understandings of what a person is.

This chapter draws its inspiration from Donald Tuzin's ethnographic vision, focused as it is on understanding cultural themes as they are expressed in individuals' minds, with all of the contingencies of a life as lived. In his work, Tuzin emphasised that one's cultural views depend as much on the emotional conditions of one's individual experience as they do on the learned cultural systems. His paper 'Of the Resemblance of Fathers to Their Children: The Roots of Primitivism in Middle-Childhood Enculturation' (1990) presents a clear example of his point of view. In that work on the psychological impact of beliefs in spirits, he looked to the context in which those beliefs were first learned in middle childhood. His point is that the experiential context of a child is very different from that of adults, and that experience is what shapes the emotional valences of adults' beliefs. He writes: 'Children creatively interpret received cultural elements in such a way as to give substance to their emergent sense of 
identity, thus establishing an indivisible union between the person, on the one hand, and the culture that provides its ideational constituents, on the other' (Tuzin 1990:72).

To understand the emotional framework of beliefs in adults, one needs to understand the story told by those beliefs to children, for it was as children that those beliefs were first learned and understood. Children learn features of their culture from other children (Tuzin 1990:82), and the versions they learn are 'inevitably partial and distorted because they are based on limited life experiences' (p. 84). The process produces 'childish residues' in adult culture, and in that context some of the more ghoulish elements of adult culture make more sense (Tuzin 1990:99). So, in this context, the beliefs of fathersformed originally in the context of child-to-child interactions-resemble the primitivisms found in children's beliefs.

By placing beliefs in a specific ethnographic and experiential context, Tuzin's approach is one example of several recent efforts to view cultural beliefs through the lens of individual experience. Recent research in anthropology and psychology, for example, has shifted its focus to the activity of narrative production, arguing that people everywhere build stories that make a point; as the linguist Labov (1981) put it some time ago, the stories must answer the question 'So what?' Individuals use personal narrative to make sense of their lives, to negotiate among different versions of self, and to fashion responses to dominant cultural discourse. In their review of approaches to the study of personal narrative, Ochs and Capps emphasise that by using all these strategies, 'interlocutors tell personal narratives about the past primarily to understand and cope with their current concerns' (1996:25). Narratives are thus driven by motives with particular, immediate aims. Researchers across a range of analytic traditions have put forward new approaches that accommodate narrators' active attempts to use stories to place life events in a desired context. Thus, cognitive anthropologists have worked to build models of mental process that can address specific circumstances. Strauss and Quinn, for example, draw on a connectionist model for mental schemas that can be 'highly context sensitive' (1997:53). By looking at schemas as embedded in a host of associations networked together, researchers can consider specifics, so that 'the particular features of any given event can lead to different outcomes from one situation to the next' (Strauss and Quinn 1997:53). The model allows for greater attention to the 'directive force' of cultural schemas to better appreciate narrators' commitments to specific ideas at specific times (D'Andrade and Strauss 1992). At the same time, psychoanalytically informed anthropologists have looked at the often inconsistent and conflicting identities mobilised by narrators to apply to specific situations in giving life accounts (see especially, Ewing 1990, 1997). Researchers in cognitive psychology have cultivated an interest in 'taking narrative seriously' (Chase 1995) as a tool 
for better understanding mental processes. And theorists of autobiographical memory emphasise how memories of the past are mobilised through a narrative process with specific aims, so that remembered stories 'communicate what is significant in [people's] lives' in such a way as to 'seek to convince others to see some part of reality in a particular way' (Garro and Mattingly 2000:11).

When stories deal with the very personal topic of one's own childhood, it is likely that the rhetorical strategies for self-presentation will play a prominent role in the shape of the story told. The stories almost by definition seek to convey something about self-understanding. But stories of childhood also, to an exceptional degree, rely on often unarticulated ethno-psychological premises about just what a person is, so that they might serve as a particularly effective venue for exploring how local cultural forms bear on universal processes in narrative production. The challenge for the researcher is to articulate these universal features while at the same time avoiding inferences about motives that might depend on a Western model of how childhood shapes adult selfhood. So, for example, in dealing with Bumbita personal narrative, it might be appropriate to infer that a narrator is making an argument about how to understand his or her experience, but it would be inappropriate to infer that the narrator aims to build a narrative that explains personality traits or emotional preoccupations. While the stories from childhood might seek to convey something about 'who I am today', the cultural forms that underlie that self-assessment might be dramatically different across societies.

I shall use the case of a personal narrative of a Bumbita young man to pursue two separate aims. The first seeks to illustrate in a detailed way how basic Bumbita assumptions about the nature of personhood define the terms through which the narrator presents his stories from childhood. Bumbita conceptualise a person as the product of the nurturing activity of parents and others in the community, and that nurturing is conceptualised in terms of a literal transfer of substance through the activity of cultivating and providing food. Thus, the Bumbita say that people age only because their vital strength is continuously being sapped by dependents who are consuming food produced by the caretakers. They understand the process as a literal transfer of substance between generations. One implication is that a person becomes who he or she is only through a process of literally ingesting the vitality of parents and other caretakers. The Bumbita frame the moral obligations of children to their parents in these terms. You must look after your parents in old age, they say, because your own strength has caused their weakness. In the Bumbita view, it is not the case that one's personality is shaped by, say, the child-rearing priorities of one's parents; in fact, they see childhood experience as irrelevant in shaping one's character. Instead, they see one's personal vitality and integration within the community 
as the products of caretakers' vigilance in providing adequate transfers of food to dependents. I shall show how these themes underlie the narrative structure of the young man I have chosen to present.

At the same time, this young man's narratives also reveal rhetorical strategies that I believe are characteristic of personal stories everywhere. In spite of the dramatically different cultural frame for his stories of childhood, he still makes an active effort to present himself in a particular way. In this context, the local Bumbita understandings of the meaning of childhood become a backdrop for a more active, individual rhetorical move to prove a point about what the childhood experience means. My second aim in this chapter, therefore, is to draw attention to a relatively underdeveloped dimension of the universal process of rhetorical argument in narrative production. Specifically, I argue that the inevitable rhetorical dimension to telling stories requires us to look at the story as making an argument about the experience. Once we look at the arguments that underlie a given story, we have to consider also what it is that the arguments are mobilised against. In asserting a certain point about how to understand a story, the narrator seeks to suppress alternative versions. Those 'suppressed meanings' (Leavitt 1995, 2007) should be integral to our analytical approach. The actual meaning of the narrative emerges only by juxtaposing the asserted argument against these suppressed meanings. The young Bumbita man who talked to me about his childhood transactions of food was at the same time constructing an argument about his place in the community. And he was building that argument to combat suppressed fears about what he suspected was actually a precarious position in that community.

\section{Transactions of Food in Bumbita Childhood Stories}

During my first weeks in Bumbita, I was struck by how easy it was to ingratiate myself with people by simply feeding them. In those early days, I had several tasks (including the large one of building my house) that had to be paid for, and while the adolescents who helped me were willing to take money for their work, I found that they seemed to feel better compensated if I simply offered them a meal at the end of the day instead. The deep significance of transactions of this kind is a well-known feature of Melanesian social relations. On one level, it is not surprising that in exchange-based societies people would see gifts as potent declarations of goodwill. In talking about the Kaluli of the Papuan Plateau, for example, Schieffelin (1976:150) notes: As human relationships are actualized and mediated through gifts of food and material wealth, so these things come to stand for what is deeply felt in human relationships.' Gifts convey concern. 
To appreciate what gift relations actually mean for Melanesians, it is necessary, however, to look as well at how such relations come to participate in people's most intimate sense of being. Marilyn Strathern has described how Melanesians see transactions as ways of transporting parts of one's being in a literal sense. She distinguishes 'mediated' exchange of valuables where objects 'circulate as parts of persons' (1988:192) from 'unmediated' exchange where the products of work contribute directly to the creation of others (such as in the case of parents feeding children) (pp. 177-8, passim). In both types of exchange, the essence of being is conveyed from person to person through transaction. In the first case, the objects themselves determine a temporary state of relations between people (as 'donors' or 'recipients'). Over time, as gifts pass back and forth, the relations are reciprocal. But in the second case, the unmediated transfer of substance means the donor has a direct influence on the minds and bodies of the recipients, so their status as recipients is more enduring. As a result, 'the capacity to have an unmediated effect creates a distinguishing asymmetry between the parties' (Strathern 1988:178). This asymmetrical relationship, which finds its prototype in relations between parents and children, provides the conceptual frame for Bumbita thoughts about their childhood experiences.

It is not simply that children, in accepting food from their parents and others, learn about unmediated exchange of substance; they also come to associate those ideas with themes and conflicts that arise from the pragmatics of growing up. In the case I present here, the young Bumbita man related to me a series of vignettes from his childhood focusing on the theme of his integration into a community of peers through transactions with food. His stories draw upon Bumbita cultural themes emphasising how transactions of food provided, through a literal transfer of substance, a vehicle for integrating oneself into the community. He emphasises how, through guile and manipulation, he was able to compel older boys to accept him into their social group. His stories argue implicitly that he was successful.

The episode was related by Aminguh, a young man in his early twenties. He was the youngest son of a powerful village leader who served several years as village councillor. The father died when Aminguh was in his early teens. Of the informants with whom I conducted detailed personal interviews, Aminguh was among the most enthusiastic. Occasionally, he would wake me up to talk in the middle of the night, and often he said he had thought a lot between sessions about what he wanted to tell me in the next interview. By the time of my departure, we were close friends. After one of my early formal interviews with him, I told him that the next time I would like him to tell me some stories that he remembered from his childhood. I told him just to tell me anything that he remembered. He returned the next week and began relating to me a whole series of childhood incidents. All together, they took up the better part of three 
interviews. He seemed to want to entertain me with the humour of a child's plight. He told of cutting himself in his fumbling attempts to learn to use a bush knife, of eating food that made him sick to his stomach, of burning himself in cooking fires. In taking this perspective, he also sought to capture the feelings and thoughts of a young child as opposed to those of an adult. His stories of relations with others therefore conveyed his experience with an immediacy often lacking in similar stories from other informants.

He began his rendition of his childhood by relating to me a series of incidents involving his attempts to follow along with his classificatory brothers in their forays into the bush to find food. Most of his stories shared themes about wanting to be included. Because of Bumbita cultural assumptions about defining group membership through sharing of substance accomplished through transactions of food, Aminguh used the theme of transactions of food to articulate his points about being included in the group. By manipulating his brothers into sharing food with him, he became a part of their group. What is striking about his account from a Western perspective is how irrelevant motives are. Westerners would consider acceptance through manipulation as a decidedly unsatisfying way of becoming a part of a group. From our perspective, the important thing would be whether the brothers wanted to include Aminguh in their group - the extent to which Aminguh could, through personality traits or commendable personal action, convince his brothers that he should be a part of their group. But such issues matter little in Aminguh's story. The first incident goes as follows:

We went to cut the bush. At this time I didn't wear any trousers [he was about ten years old at the time]. When we cut gardens, we would work at night, with the moon full. Sirimbom, Rengur and some others, we would work at night, cutting the bush. I was just a kid so I just sat and looked at them [as they worked]. One morning [my 'brothers'] went off to find eggs from wild fowl. I wanted to go with them, but they pushed me away, pushed me away, so I just sat down [to wait for them]. Then they came back to cook, in the afternoon, to cook the eggs and wild fowl they had caught. I got up and walked very quietly and sat at the back of Ohitum ['eB']. I sat there and they talked among themselves, saying, 'Hey, you all eat in a hurry, the kid's going to come back soon!' They started to eat and I sat at the base of a tree and then hit a piece of sugar cane against the tree. They turned to see me and then they got up to hit me now! Mangen ['eB'] and the others chased me up the hill, but I didn't go away. I just waited for them to go back so I could come up and they would have to give me a piece of meat. I came up and Sirimbom ['yB', but older than A.] gave me some and then told me to leave, and I said, 'I am going to tell my father, say that they are eating wild fowl' - you see 
they had forbidden them from eating it because they had already done [their initiations]. I said that I'd go tell them and they started cajoling ['grisim'] me, telling me not to. They sat there and gave me a piece of meat - Sirimbom had given me some before - but now [the two others] gave me some and they said, 'You can't go and tell them, just keep quiet about it.' We ate together, finished, and we came on up.

There are two avenues that I wish to pursue here in explicating this incident. The first is to assess Aminguh's characterisation of the people's motives and interactions as an indication of his general view of human behaviour as framed by Bumbita understandings about the significance of transactions of food. The second is to identify the social predicament his story works to fortify him against and to address what suppressed meanings might motivate him to frame his stories in the way he does.

Aminguh's immediate goal here, as he presents it, is to finagle some food out of his 'brothers'. But the details he selects indicate that for him there is an association between getting the food and being a part of the group - that is, if he gets the food, that means he is one of them. He begins by saying, 'We would work at night', implying that he remembers being one of this group of classificatory brothers. But then he immediately establishes a narrative tension by throwing his affiliation with the group into doubt, stating that when they went off on that cherished social activity of boys, finding food, 'They pushed me away'. When the brothers return, he hides from them in order to overhear them conspiring to keep from him the food they have caught. He includes this sequence in the story to verify that their hiding the food from him is an active exclusion, not simply an oversight. For him, that situation is intolerable. He reacts by getting them to share the food with him. It is only then that he can feel included.

In telling how he managed to get them to share, Aminguh reveals his understanding of human behaviour in such situations. First, his brothers do not have any prior inclination to share with him despite his being their kin. They try to eat in a hurry in order to avoid having to give him some. He characterises them as being self-interested, excluding him so as not to have to share. Second, they respond to his efforts to reveal them. He first distracts them so that they will know that he has heard them trying to eat behind his back, and then, after they chase him, he continues to come back because he knows that if he comes back, 'They would have to give me a piece of meat' - even though they were capable of sending him off completely, using their fists. His message here is that people will not share unless they are forced into doing so. And even then that is not sufficient since they only give him 'some' - that is, not an equal portion. Getting the equal portion requires further manipulation. Here he uses the threat that little boys often use, the same threat that keeps them from being 
included in the group to begin with: he says that he will tell their parents that they are eating forbidden food. This last manipulation produces the desired results. Suddenly, the older boys take him in and give him his proper share of the food, and they all go off together back to their camp. Aminguh sketches here a pattern of interaction that shows individuals acting in their own interests at the expense of others but at the same time responding well to manipulation and to the threat of being exposed. Through this manipulation, Aminguh gets his food and at the same time is included in the group.

Aminguh's act of manipulation raises another theme to his story, one that is implicit but important to identify given his position as the son of a deceased village counsellor and leader. He gets his way through artful manipulation, and successful manipulation is in the Melanesian context a measure of personal power. For example, Bumbita yam growers manipulate ancestral spirits through their yam magic, coercing them to help the yams grow. Similarly, successful leaders manipulate others into doing their bidding. In Melanesia, 'status in the local community is achieved through processes of political manipulation. Through these manipulations a man becomes a big man. Successful big men become village councilors' (Barnett 1979:770). Missing are the negative connotations associated with political manipulation in the Western context. Aminguh's stories here are clearly success stories. He manages to manipulate his 'brothers' into sharing with him, and in so doing he shows himself to have some of the ingenuity recognised as characteristics of village leaders.

It is important to note here that once he does get them to share with him, he sees the conflict as resolved and the previous rejection as nullified. It is this characteristic of the story that makes it seem so peculiar when looked at through Western assumptions about what it means to belong to a group. To a Western audience, such a story would convey at best a tenuous resolution to the predicament of social belonging. Aminguh's having to resort to guile and manipulation would be seen as a sign that he had failed in a fundamental way to resolve the issue. It would be tempting to view his story as an appeal to sympathy due to an unfortunate, even tragic, instance of social rejection. But Aminguh attaches no such meanings to his story. For him, the story is a success story about exercising leadership in becoming a part of his group of brothers. What matters is the actual transaction of food; how the food was obtained is not an issue for him. In fact, the dynamic that Aminguh presents from his childhood recapitulates Bumbita understandings of prototypical negotiations between children and parents over food. According to Bumbita understandings of child-rearing patterns, when children are young, they learn that conflicts with their parents can be resolved by demanding food, that eventually their parents will 'feel sorry' for them and give in to the demands. Parents regularly describe their own behaviour as eventual acquiescence to persistent pestering. 
Westerners regard such patterns as evidence of some kind of failing on the part of parents. Manipulation of parents by children is part of the Western model of what might go into 'spoiling' a child. But in the Bumbita view, guile and manipulation to obtain the transaction of desired food are a fundamental part of the process of transaction. Young children do it with their parents, and once they reach older childhood they extend this model of interaction to relations with peers, describing more subtle methods of manipulation. This manipulation becomes a basis for exercising leadership among men.

An appreciation of local Bumbita understandings of transactions over food is therefore pivotal in understanding the significance of Aminguh's story. Only by looking through the local cultural lens can one see the story's heroic features. It is a story that begins with a rift in social relations causing feelings of rejection, a manipulation of others through guile and persistence, and a successful resolution of the conflict through the proper sharing of food even when done grudgingly.

\section{Suppressed Meanings}

Anthropologists might at one time have used a story such as Aminguh's to illustrate prevailing features of local cultural models or schemas. But in recent years attention has shifted to identifying some of the contingencies of personal narrative that might shape how it appears at any given point in time. Personal narratives present an understanding of the self, but they do so through a rhetorical process that seeks to foreground certain themes and suppress others. Psychologists following the pioneering work of Jerome Bruner have sought to articulate some of the activities involved in presenting a particular version of the self. Bruner writes, in fact, that ' $[\mathrm{r}]$ hetoric is as pervasive a feature of Self construction as narrative itself, and though we tend to dismiss it on moral grounds as mere "self-justification", such dismissals fail to recognize to what degree the concept of Self (and autobiography itself) is a form of apologia' (Bruner 1994:49). Researchers, he argues, have to recognise that such self-justification is a fundamental characteristic of how people everywhere think about themselves. Behind the activity of self-justification lie alternative scenarios, what I have called 'suppressed meanings', which contribute to the shape of the story. As Susan Chase (1995) puts it, any asserted story of self contains a 'submerged' story that might point to a 'feeling of inadequacy'. She argues that 'as interviewers we need to attend to submerged stories and invite their telling' (Chase 1995:17).

So what possible submerged story or suppressed meanings might we infer from Aminguh's stories of his childhood? Without a detailed account of his entire life, I can only hint at suggestions, but there are clues even in the accounts that he presents here. First, it is important to point out that the themes articulated in the 
story above appear over and over in his stories about his childhood. Establishing a sense of belonging to the peer group was a preoccupation. His other stories of childhood show what he experienced there as part of a more general pattern. So, for example, after relating the incident above, he went on to talk about the time his friends and 'brothers' caught some fish and another bird. Aminguh again tried to tag along, saying that they sent him off, "They always got rid of

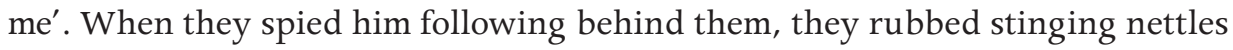
on him and threw him into the water. When they caught a bird, he says, 'They left me behind, they didn't think of me, just thinking of their bird. I walked along [he imitates sniffling] as if I were about to cry.' Afterwards, they prepared to cook the bird but did not show it to him, lying to him and keeping an eye on him so that he could not see what they were cooking. But by astutely looking at the materials they used for cooking, he surmised that they must have caught something substantial. When they offered him some fish and told him to leave, he said, 'No, I want to see what it is that you are planning to bake', and he told them again that he would tell their parents if he did not get some. So they included him, saying, 'Sit down, sit down, sit down', and they all ate together.

In a third incident under similar circumstances, his 'brother' sneaked a pigeon to Aminguh before the others returned and told him to hurry and eat because otherwise '[w]hen they come they'll see that you've already eaten and they'll say that you've already had enough'. He cooked and ate the bird in a hurry and then received a small share of the catch of the others when they returned. After receiving his share, he said, 'Hey, give me another one!' and they said, 'That's enough for you!' He then went on to describe how in the morning they discovered the feathers from the first bird he had eaten and thus saw that he had manipulated them into sharing when he had already eaten a large portion on his own. He portrays himself here as being as selfish as the others by trying to get more than his share. After he had related all of these incidents, I ventured the question, 'Why were they always trying to get rid of you?' He responded:

Because they said I was just a kid. It wouldn't be good if I were to tell on them, tell the women and the other kids, saying, 'These guys here are guys who hide and eat meat', to shame them, so that the women would say, 'Hey, we don't like these guys who eat meat', it's like that.

Here the question of who trusts whom runs the other way around. Before, Aminguh could not trust them to share the food because of their greed. Now, he says that they could not trust him to keep their eating a secret. The implication is that one should not expect to be able to trust other people; he portrays himself as unreliable as well. In Aminguh's view, it is the inability to trust others that lies behind the difficulties people have in accepting others. And, of course, Aminguh's subsequent manipulation only reinforces that view among his peers. 
These stories carry some persistent patterns, and Aminguh consistently presented them to me through constructing a version of himself as a child, a version he wanted me to see and accept. He invited me to share in his childhood frustrations at being shunned by his brothers and peers and then presented for me a 'childhood Aminguh' who, through his skill at guile and manipulation, was able (temporarily at least) to overcome the exclusion he felt. These vignettes cannot accurately reflect Aminguh's overall childhood experience, but they can reflect his interpretation of important features of that experience and identify enduring issues of conflict. Taken together, they suggest that, for him at least, being outside the group, excluded by others, was a problem that he felt he needed to address. The tension in each incident derives from his setting himself in opposition to the group. In each case it is Aminguh versus 'them', with the 'them' being a solidified group of peers. Their exclusion of him makes him feel hurt so that he 'sniffles' or murmurs stoically to himself, 'It's all right, it's nothing'. And each time he eventually responds by revealing that he knows they are hiding food from him and by eventually manipulating them into letting him join them.

Taken together, the series of vignettes does not imply a deeply psychological defence structure against unacceptable meanings. But they do have a coherent set of points-likely cultivated in his own private reflections on his past experience - that insist on a particular interpretation of the events described. The central argument is that he, through his own individual initiative, was able to coerce his brothers into accepting him into the group. In the Bumbita cultural context, transfers of substance, through the sharing of food, imply a fundamental sharing of being that Aminguh accomplishes through his own initiative. Once his argument is understood in that context, it is possible to infer the alternative scenarios that might be suppressed. The critical issue is what he can actually accomplish through individual initiative. Lurking behind the stories is the possibility that personal initiative is not in fact sufficient for becoming a part of the group. In fact, the Bumbita cultural model of substance transfer implies that individual initiative is not sufficient. All Bumbita are fundamentally dependent upon the nurturing activities of others.

It turns out that, in Aminguh's case, the premature death of his father left him with a profound sense of dislocation that he was wrestling with throughout our interviews together. As he understood it, maturing without a father entailed the risk that he would not be able to acquire the substance and knowledge that would make him a complete adult. While the vehicles for the transfer of vitality are primarily those of food and energy spent on the cultivation of food, the Bumbita tend to see other transfers, such as ritual knowledge, magic and wisdom, as a form of nurturing essential to the proper relationship between father and son. In the case of ritual knowledge and magic, the scrupulous secrecy and the 
competitive uses of such things require that one learn about them from just a very few sources, and the most important is one's father. Certain techniques of yam magic, for example, are highly individual and are passed from fathers to their sons. Such magic is regarded as essential to harvesting abundant crops. The importance of acquiring knowledge from one's own father is also reflected in the magical potency of heirlooms such as axes, nets for hunting pigs, and curing packets. These objects are imbued with the essence of clan ancestors so that they are not effective if used by anyone besides an appropriate heir. Young men also rely on more informal practical wisdom about how to live with women and how to succeed politically. The Bumbita feel that anyone else besides their own fathers will be unwilling to impart such knowledge. Aminguh, in his interviews with me, communicated a profound anxiety over being able to take his father's place in the community without his father's guidance and continued transfer of substance. Here is an example of how he talked about his position when lamenting the death of his father:

I am here and...there is no other 'father' to come and teach me things. I know, each father must teach his own children about everything. If he goes wrong like this, his father will say, 'You must do it this way.' That's how it is, so I think of this all the time. I think, 'Why did he die like that, he didn't want to wait until I was big, like I am now, so that he could teach me first and then later go ahead and die?'

He starts by saying that his clan fathers (all of whom have died) might have taught him had they lived, but then reflects that really it is only his own father who would have been likely to do so consistently. Clan 'fathers' have their own sons. Aminguh's feeling of loss is accentuated by the ideology that parents create adults out of their children through a transfer of substance, vitality and energy. Here he speaks only of ritual knowledge and wisdom, but his understanding of relationships between generations leads him to see the loss of his father's teachings as leaving him incomplete in some fundamental way. When I asked him if he thought that he would be like his father, he said, 'I want to become like him, I think that way. I think, will I become like him or not? If I had gotten some stories from him, then I could be like him. But I have missed out, so I can't know.'

What is striking about these comments is the explicit fear that he will not, through his own initiative, be able to take his proper place in the community. What he is unsure about is whether he has already acquired enough of what it takes to be an effective adult man. In his mind, the jury is still out; he says, 'I can't know'. Masculine vitality is for Bumbita men a fundamental feature of selfassessment. Men learn to gauge their own effectiveness as males by observing 
the products of their own individual initiative. If a yam crop yields abundance, a man can infer that he has the requisite vitality to cause that result. The proof lies in the results of individual initiative.

It is in this context that his stories of guile and manipulation take on a new meaning. In being successful at getting the young men to include him, he is in essence re-enacting an activity appropriate for village leaders, for people like his own father. His stories are of a heroic nature, with the young Aminguh successfully getting his way. In framing his stories in this way, he is suppressing the doubts that we otherwise know concern him, that the loss of his father has meant he has lost the training necessary to become a village leader himself. The stories are a way for him to indirectly play out the role of a successful leader, who, through manipulation, gets others to give him what he wants and becomes a part of the community in the process.

Aminguh's stories of his childhood, when understood now in the context of a preoccupation with masculine vitality, become narratives through which he seeks to prove to himself that he already has enough personal effectiveness to integrate himself into the group without the continued guidance from his father. He understands that he now depends on the same community of classificatory brothers that he successfully manipulated in his stories about their childhood interactions. His stories of success fortify him against fears that his own personal initiative will be insufficient to make him a successful adult.

Thus, by understanding Aminguh's childhood stories as active attempts to define reality in a particular way, we can better appreciate the fundamental issues that define his experience.

\section{Conclusion}

I have used Aminguh's case material to illustrate the value of attending to the active rhetorical dimension of narrative construction. I have deliberately chosen stories that do not call attention to their argumentative dimension. It was not the case that Aminguh insisted to me that I must understand these stories in a particular way. He was not aware of building any strong argument. Nevertheless, the stories do reveal a consistent set of themes pointing to a particular interpretation of childhood events. I have tried to show that an appreciation of Bumbita cultural understandings of the process of development in childhood is essential to the interpretation of themes from childhood stories. Without a sense of those understandings, Aminguh's stories, as stated, make little sense. But at the same time the stories illustrate universal features of the narrative process that I argue should be applied to narrative constructions across cultures. Appreciation of Aminguh's experience requires attending to 
psychologically based motives that contribute to the structure of his stories. He presents a particular version of events in an effort to convince himself of his own personal effectiveness in manipulating and ultimately relating to his close relatives. The version he presents is a fortified one, built to defend against an alternative suppressed version that would leave his personal effectiveness in doubt. Those suppressed meanings emerge in other contexts, such as when he invites my commiseration over his predicament of having to grow up without a father. Aminguh's childhood stories, then, do rely on cultural meta-narratives, but they also - when viewed with their rhetorical intent as a part of the analytical calculus - provide a window on experience.

\section{References}

Barnett, Tony 1979. Politics and Planning Rhetoric in Papua New Guinea. Economic Development and Cultural Change 27(4):769-84.

Bruner, Jerome 1994. The 'Remembered' Self. In Ulric Neisser and Robyn Fivush (eds) The Remembering Self: Construction and Accuracy in the Self-Narrative, pp. 41-54. Cambridge: Cambridge University Press.

Chase, Susan E. 1995. Taking Narratives Seriously: Consequences for Method and Theory in Interview Studies. In Ruthellen Josselson and Amia Leiblich (eds) Interpreting Experience: The Narrative Study of Lives, pp. 1-26. Thousand Oaks, Calif.: Sage.

D'Andrade, Roy and Claudia Strauss (eds) 1992. Human Motives and Cultural Models. Cambridge: Cambridge University Press.

Ewing, Katherine P. 1990. The Illusion of Wholeness: Culture, Self, and the Experience of Inconsistency. Ethos 18:251-78.

Ewing, Katherine P. 1997. Arguing Sainthood: Psychoanalysis, Modernity, and Islam. Durham, NC: Duke University Press.

Garro, Linda C. and Cheryl Mattingly (eds) 2000. Narrative and the Cultural Construction of Illness and Healing. Berkeley: University of California Press.

Labov, William 1981. Speech Actions and Reactions in Personal Narrative. In Deborah Tannen (ed.) Analyzing Discourse: Text and Talk, pp. 219-47. Washington, DC: Georgetown University Press.

Leavitt, Stephen C. 1995. Suppressed Meanings in Narratives About Suffering: A Case from Papua New Guinea. Anthropology and Humanism 20(2):1-20. 
Leavitt, Stephen C. 2007. Positioned Meanings in Personal Narratives. In Jurg Wassmann and Katharina Stockhaus (eds) Experiencing New Worlds, pp. 7894. New York: Berghahn Books.

Ochs, Elinor and Lisa Capps 1996. Narrating the Self. Annual Reviews of Anthropology 25:19-43.

Schieffelin, Edward L. 1976. The Sorrow of the Lonely and the Burning of the Dancers. New York: St Martin's Press.

Strathern, Marilyn 1988. The Gender of the Gift. Berkeley: University of California Press.

Strauss, Claudia and Naomi Quinn 1997. A Cognitive Theory of Cultural Meaning. Cambridge: Cambridge University Press.

Tuzin, Donald 1990. Of the Resemblance of Fathers to Their Children: The Roots of Primitivism in Middle-Childhood Enculturation. In L. Bryce Boyer and Simon Grolnick (eds) The Psychoanalytic Study of Society. Volume 15: Essays in Honor of Paul Parin, pp. 69-103. Hillsdale, NJ: Analytic Press. 